Gut, 1979, 20, 531-537

Case report

\title{
Idiopathic portal hypertension (perisinusoidal fibrosis) after renal transplantation
}

\author{
C. NATAF, G. FELDMANN, D. LEBREC, C. DEGOTT, J.-M. DESCAMPS, \\ B. RUEFF, AND J.-P. BENHAMOUI
}

From The Unité de Recherches de Physiopathologie Hépatique (INSERM), Hôpital Beaujon, Clichy; the Service d'Anatomie et de Cytologie Pathologiques, Hôpital Beaujon, Clichy; and the Département de Thérapeutique Néphrologique, Hôpital Necker, Paris, France

SUMMARY We report the cases of two renal transplant recipients suffering from idiopathic portal hypertension, a condition characterised by increased portal venous pressure in the absence of both histological lesion of the liver and obstruction of the portal vein. In these two patients, perisinusoidal fibrosis, invisible by light microscopy, was demonstrated by electron microscopy; it is suggested that partial obstruction of hepatic sinusoids by perisinusoidal fibrosis could be the mechanism for increased portal venous pressure in all the patients with idiopathic portal hypertension. In these two patients, who received 6-mercaptopurine and azathioprine, perisinusoidal fibrosis might be the consequence of prolonged administration of these drugs.

Idiopathic portal hypertension is a condition characterised by increased portal venous pressure in the absence of both histological lesion of the liver and obstruction of the portal vein. The purposes of this paper are (1) to point out that idiopathic portal hypertension can develop in renal transplant recipients, (2) to show that the increase in portal venous pressure results from perisinusoidal fibrosis, invisible by light microscopy and demonstrable only by electron microscopy, and (3) to offer the hypothesis that perisinusoidal fibrosis might be the consequence of prolonged administration of 6mercaptopurine and azathioprine or of immune reactions related to renal transplantation.

\section{Case reports}

\section{CASE 1}

The patient, suffering from renal failure due to chronic pyelonephritis, was treated by renal transplantation in 1964, when he was aged 23 years. After transplantation, he received betamethasone, $10-30 \mathrm{mg}$ per day, and azathioprine, $100-150 \mathrm{mg}$ per day, until November 1974. In October 1971 he had an episode of gastrointestinal bleeding due to

\footnotetext{
${ }^{1}$ Address for reprint requests: Dr J.-P. Benhamou, Hôpital Beaujon, 92118 Clichy, France.
}

Received for publication 18 January 1979 ruptured oesophageal varices demonstrated by endoscopy. In June 1973 transient ascites occurred. From November 1974 renal failure developed progressively as the consequence of chronic rejection of the renal transplant; administration of betamethasone was maintained until September 1975. In August 1975 the patient suffered a second episode of gastrointestinal bleeding; the size of the liver was clinically normal; the liver function tests were normal, except for a slight increase in serum glutamic pyruvic transaminase (42 IU, normal: 5-20) and a decrease in BSP fractional clearance $\left(0.060 \mathrm{~min}^{-1}\right.$, normal: $\left.0 \cdot 110-0 \cdot 180\right)$; hepatitis B surface antigen and antibody, looked for by radioimmunoassay, were absent; the venous phase of coeliac and supramesenteric arteriography showed large oesophageal and gastric varices and a patent portal vein. In September 1975 a third and a fourth episode of gastrointestinal bleeding occurred: endoscopy showed that bleeding was due to ruptured oesophageal varices; end-toside portacaval shunt was performed. At surgery, a large liver specimen was taken: light microscopy showed normal liver histology (Fig. 1); electron microscopy demonstrated fibrosis within all the spaces of Disse which were examined (Fig. 2). Since October 1975, the patient had suffered from severe renal failure and was treated by haemodialysis. In December 1975, hepatic vein catheterisation was 


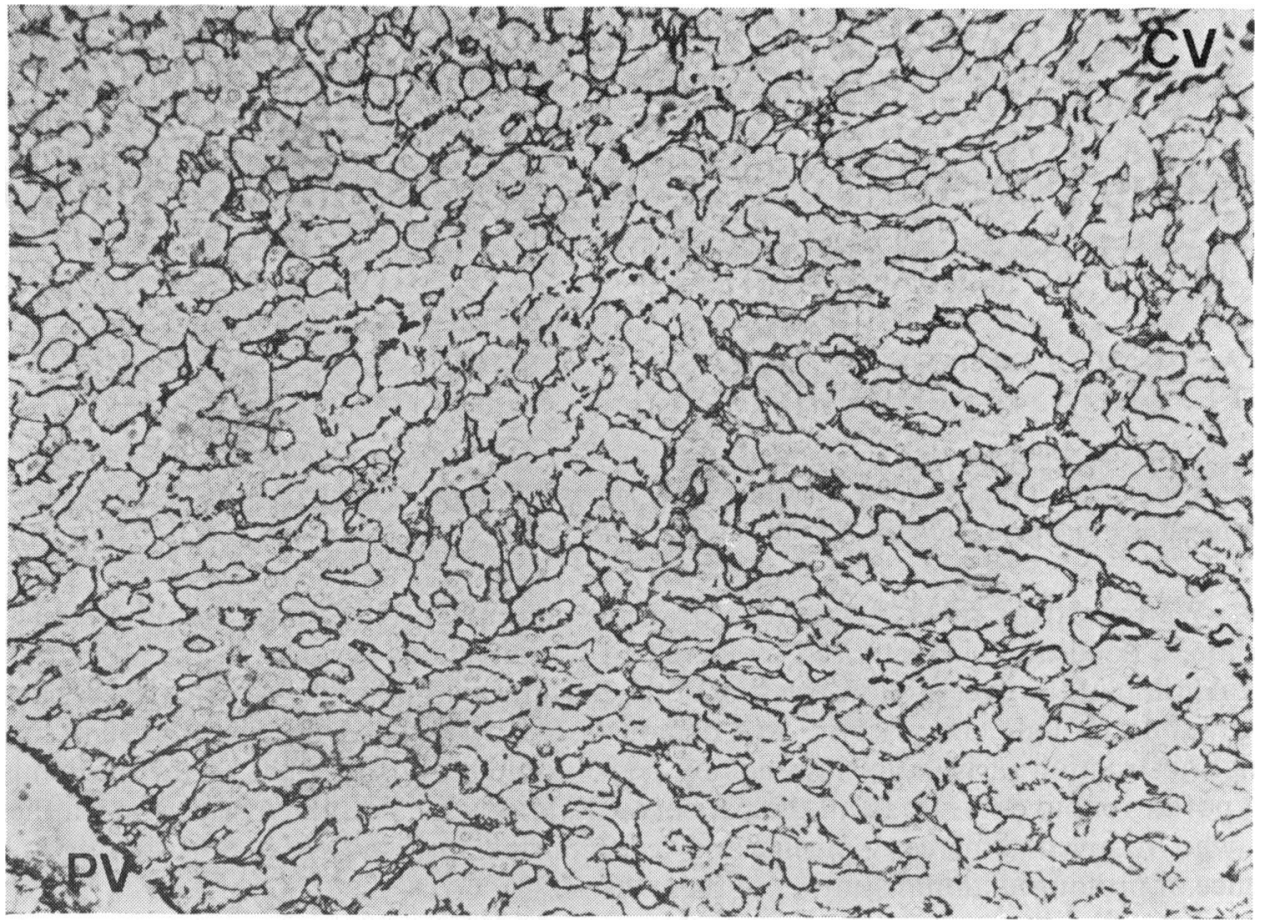

Fig. 1 Case 1. Light microscopy shows normal liver. Portal vein, PV; centrilobular vein, $C V$. Reticulin staining, $\times 170$ (original magnification).

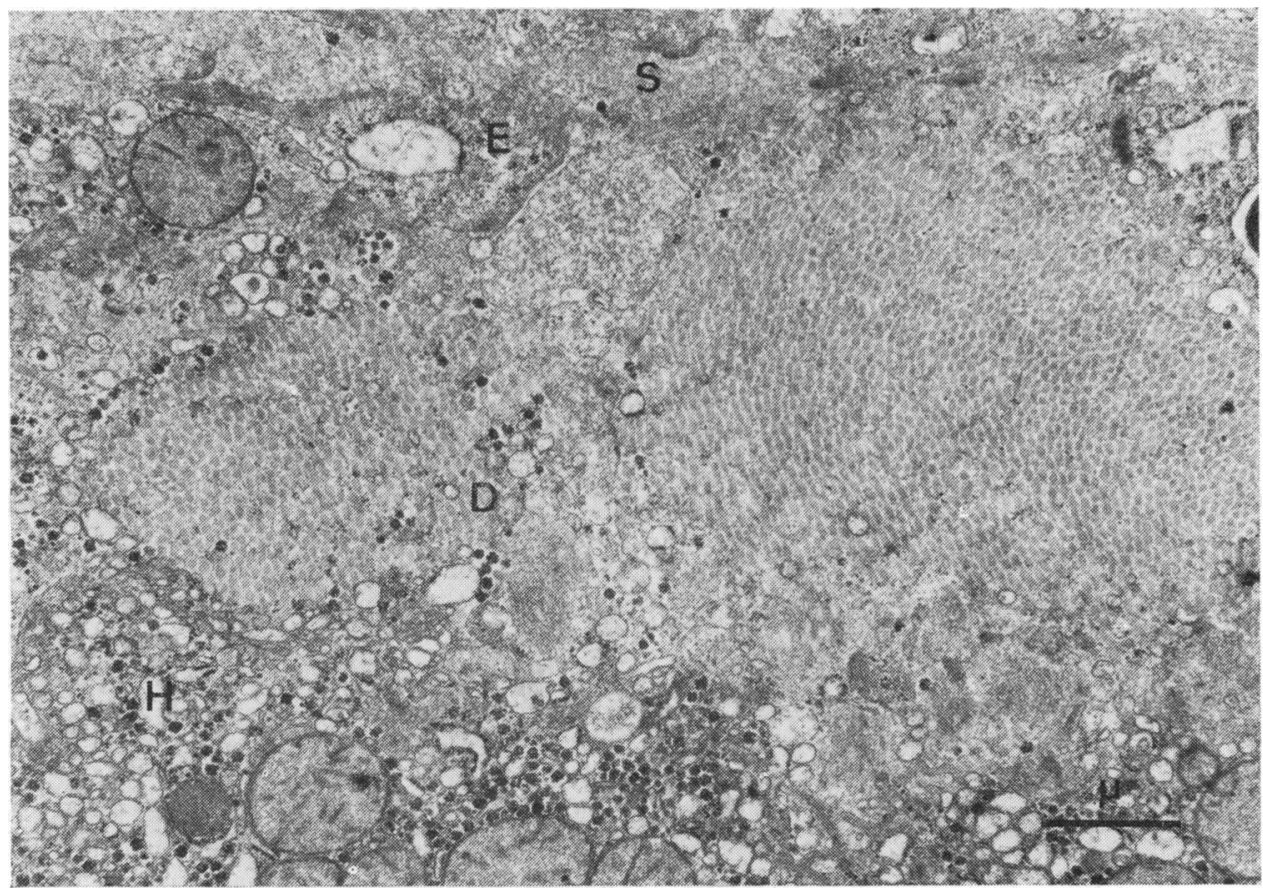

Fig. 2 Case 1. Electron microscopy of the same liver specimen as that shown in Fig. 1 demonstrates the presence of abnormally abundant collagen fibres in the space of Disse (D). Endothelial cell, E; sinusoid, $S$; hepatocyte, $H$. 
performed; free and wedged hepatic venous pressures were 2 and $11 \mathrm{~mm} \mathrm{Hg}$, respectively; the difference, $9 \mathrm{~mm} \mathrm{Hg}$, is distinctly higher than the upper limit of the normal range $(1-3 \mathrm{~mm} \mathrm{Hg})$; light microscopic examination of a liver specimen taken by needle biopsy demonstrated fibrosis (Fig. 3). Until December 1977 no other episode of gastrointestinal bleeding occurred.

\section{CASE 2}

In September 1970, when the patient was aged 23 years, he was recognised to be suffering from focal glomerulonephritis and was treated with prednisolone, $50 \mathrm{mg}$ per day, and 6-mercaptopurine, $75 \mathrm{mg}$ per day, until December 1972. Then, the administration of both drugs was interrupted and treatment by haemodialysis was started. In January 1974, renal transplantation was performed. After transplantation, the patient received azathioprine, 100$150 \mathrm{mg}$ per day, and prednisone, $15-25 \mathrm{mg}$ per day, or betamethasone, $10 \mathrm{mg}$ per day, until December 1977. In October 1975, an episode of massive gastrointestinal bleeding occurred; endoscopy showed that bleeding resulted from ruptured oesophageal varices; the liver function tests, in- cluding serum glutamic pyruvic transaminases and BSP fractional clearance, were normal; hepatitis B surface antigen and antibody, looked for by radioimmunoassay, were absent; the venous phase of coeliac and supramesenteric arteriography showed large oesophageal varices and patent portal vein. In December 1975 end-to-side portaval shunt was performed. Light microscopy of a liver specimen taken at surgery showed normal liver histology (Fig. 4); electron microscopy demonstrated fibrosis within almost all the spaces of Disse which were examined (Fig. 5). From December 1975 to December 1977, no further episode of gastrointestinal bleeding occurred.

\section{Discussion}

Idiopathic portal hypertension is defined by the association of (1) increased portal venous pressure, (2) patent portal vein, and (3) histologically normä liver. Cases meeting these criteria have been reported under various designations: essential portal hypertension (Benhamou et al., 1962), sinusoidal portal hypertension (Kluge et al., 1970), intermittent portal hypertension (Mendenhall et al., 1974), non-

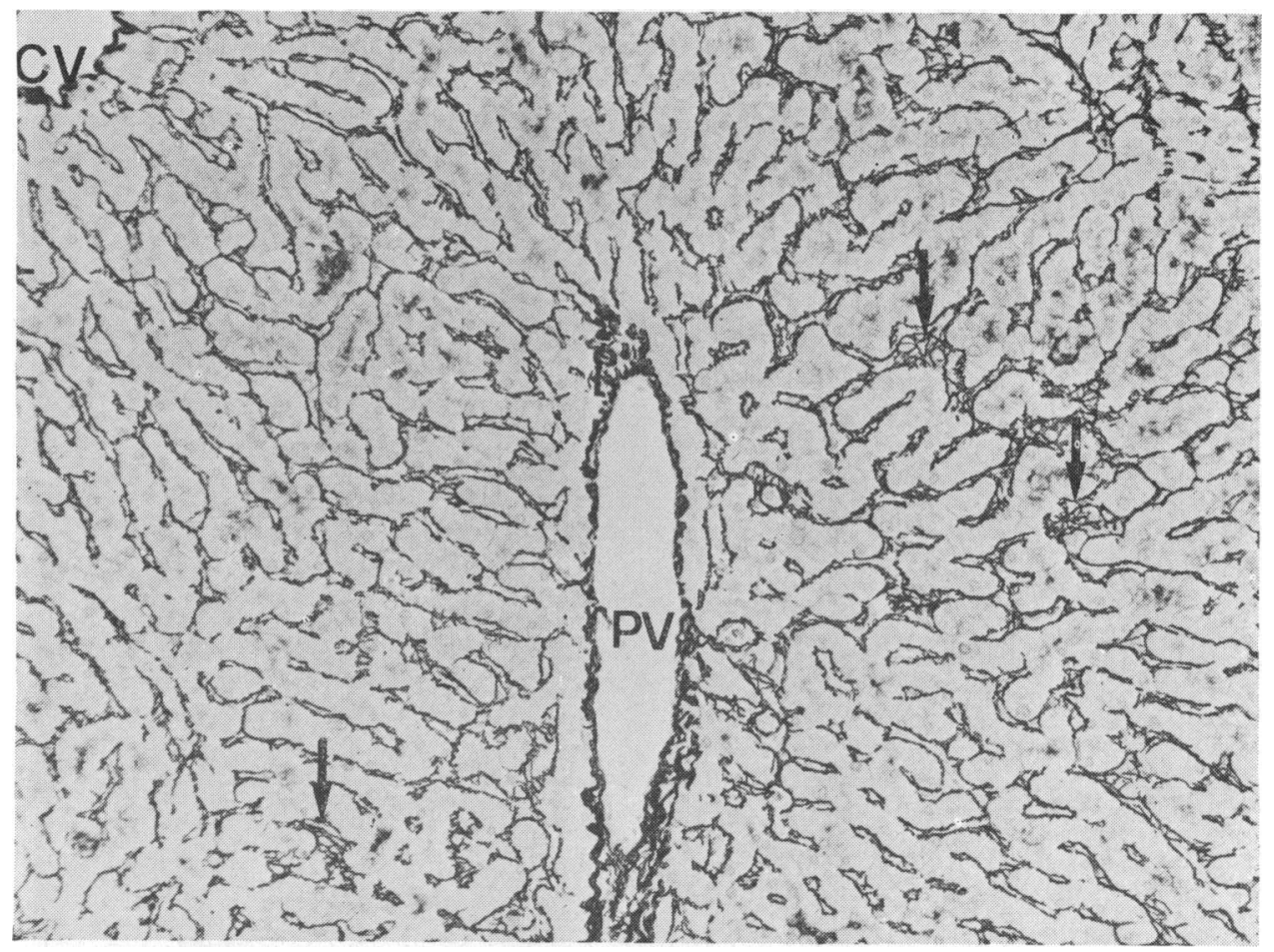

Fig. 3 Case 1. Liver specimen taken four months after the specimen shown in Fig. 1. Light microscopy shows that the reticulin network is enlarged in some places (arrows). Portal vein, PV; centrilobular vein, CV. Reticulin staining, $\times 170$ (original magnification). 
Case 2. Electron microscopy of the same liver specimen as that shown in Fig. 4 demonstrates abundant collagen fibres in the space of Disse $(D)$ and between two hepatocytes $(H)$. Endothelial cell,

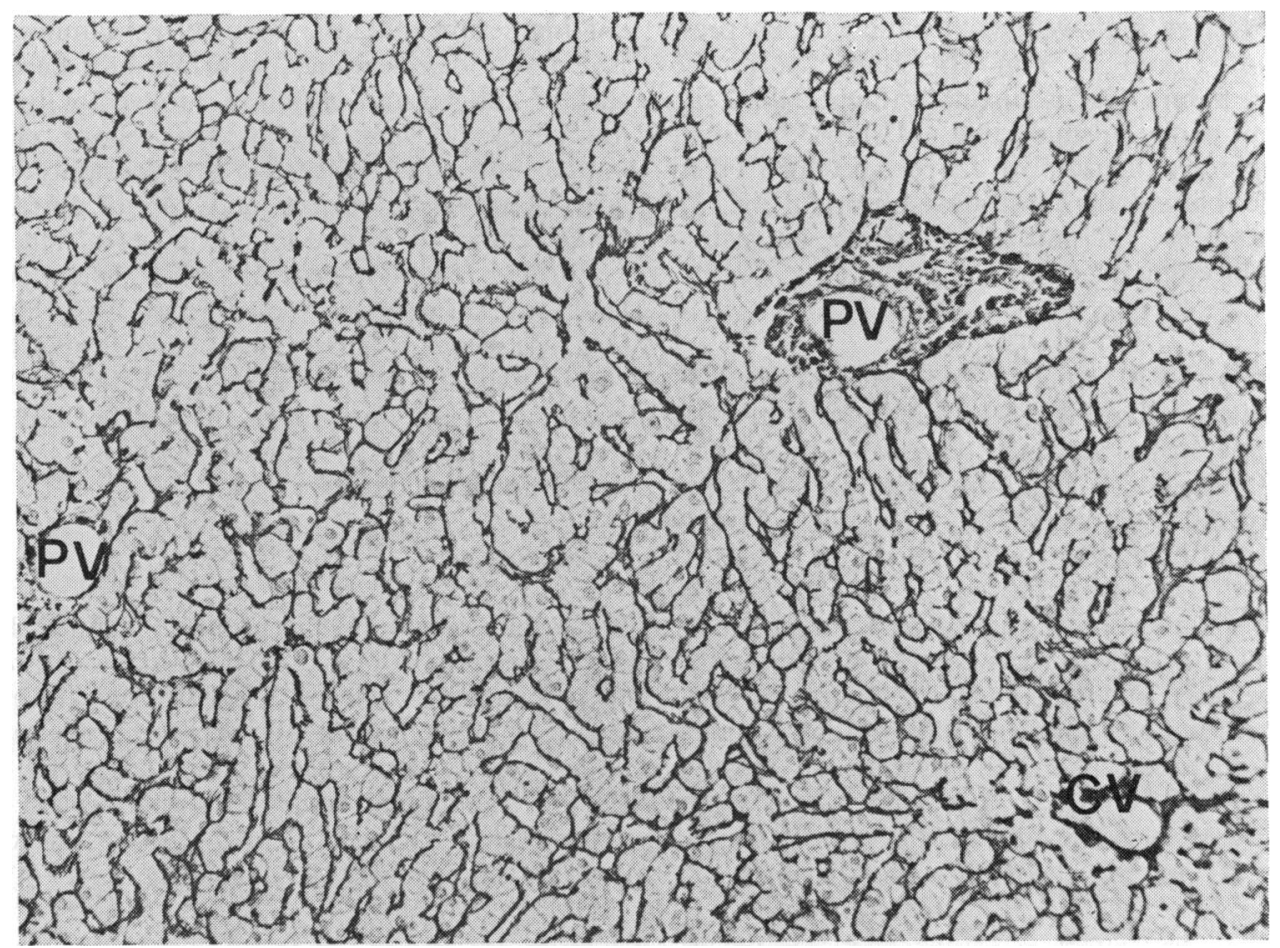

Fig. 4 Case 2. Light microscopy shows normal liver. Portal vein, $P V$; centrilobular vein, $C V$. Reticulin staining, $\times 170$ (original magnification).

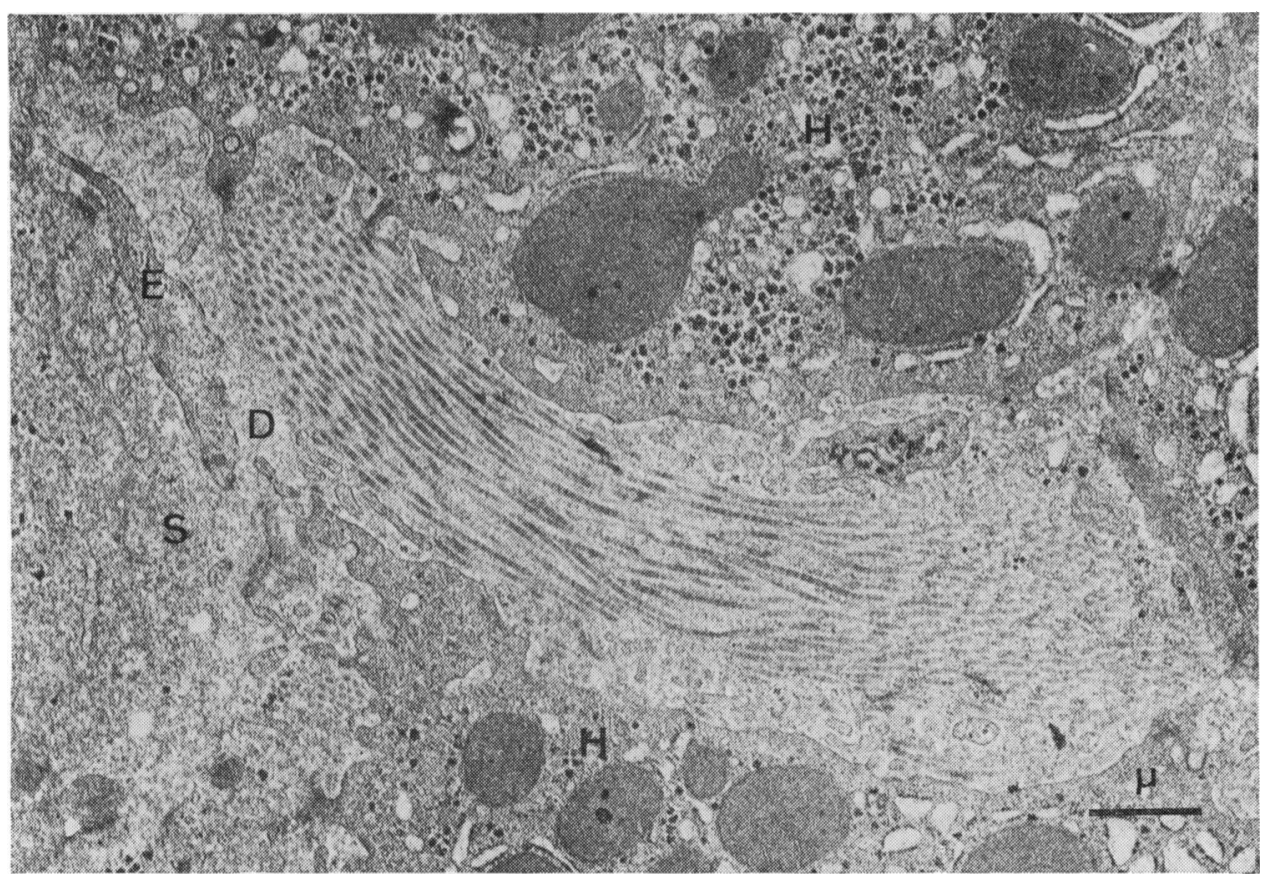
$E$; sinusoid, $S$. 
cirrhotic portal hypertension (Morris et al., 1974), non-cirrhotic portal fibrosis (Sama et al., 1971), portal hypertension in the presence of normal liver morphology (Iber, 1970), portal hypertension in the absence of both liver disease and vascular obstruction (Miller and Brandt, 1962). The prevalence of idiopathic portal hypertension seems to be low in Europe (Lortat-Jacob et al., 1967; Kluge et al., 1970; Morris et al., 1974) and North America (Tisdale et al., 1959; Mikkelsen et al., 1965; Boyer et al., 1974; Villeneuve et al., 1976), but much higher in India (Boyer et al., 1967; Sama et al., 1971) and Japan (Imanaga et al., 1962).

The main clinical manifestations of idiopathic portal hypertension are splenomegaly and bleeding oesophageal varices. Ascites is uncommon and, when present, is moderate and transient (Boyer et al., 1967; Kluge et al., 1970; Sama et al., 1971). Hepatic encephalopathy, jaundice, and spiders are absent. Liver function tests are usually normal, except for BSP elimination.

The mechanism for increased portal venous pressure in idiopathic portal hypertension is controversial. It has been suggested that portal hypertension could result from the effect of vasoactive substances on the intrahepatic portal venous network (Iber, 1969; Mendenhall et al., 1974); the nature, the source and even the existence of these vasoactive substances are, in fact, entirely conjectural; moreover, the paucity of the smooth muscular component in the wall of the intrahepatic branches of the portal vein (Rappaport, 1975) makes vasoconstriction an unlikely mechanism for portal hypertension. It has been hypothesised that idiopathic portal hypertension could be the consequence of thrombosis of intrahepatic portal venules; this hypothesis is based on angiography showing interruption of these vessels (Villeneuve et al., 1976); however, in most patients with idiopathic portal hypertension, obstruction of the intrahepatic venules has not been histologically demonstrated, even in large liver specimens such as those obtained from our patients; nevertheless, thrombosis of the intrahepatic portal venules has been found at necropsy in a certain number of patients with idiopathic portal hypertension (Boyer et al., 1974); we suggest that the absence of obstruction of the intrahepatic portal venules in the liver specimens taken by biopsy and their presence at necropsy might be explained by thrombosis being a complication of the end stage, and not the cause of, idiopathic portal hypertension.

We propose the hypothesis that idiopathic portal hypertension could be due to partial obstruction of hepatic sinusoids by perisinusoidal fibrosis, invisible by light microscopy and demonstrable only by electron microscopy. This hypothesis is consistent with, and is reinforced by, the following observations: (1) perisinusoidal fibrosis has been demonstrated in our two patients as well as all the reported cases in which electron microscopic examination has been performed (Kluge et al., 1970; Tandon et al., 1970; Sama et al., 1971); (2) increase in wedged hepatic venous pressure, observed in our two patients and in some reported cases (Boyer et al., 1967; Iber, 1970; Sama et al., 1971; Mendenhall et al., 1974; Villeneuve et al., 1976), may be reasonably ascribed to perisinusoidal fibrosis and would be hardly compatible with obstruction of the intrahepatic portal venules; (3) in our patient 1 , perisinusoidal fibrosis, initially demonstrable only by electron microscopy, was followed by more marked fibrosis, then visible by light microscopy. It is conceivable that perisinusoidal fibrosis and hepatoportal sclerosis (Mikkelsen et al., 1965) may represent the early and the late stage of a unique entity; this concept offers an explanation for the existence of intermediates between these two liver lesions and for the parallelism in the geographic distribution of idiopathic portal fibrosis and hepatoportal sclerosis (Imanaga et al., 1962; Boyer et al., 1967; Iber, 1970; Sama et al., 1971).

Decrease in BSP clearance, a disorder which was present in our patient 1 and in several reported cases (Tisdale et al., 1959; Iber, 1970; Sama et al., 1971; Morris et al., 1974; Villeneuve et al., 1976), could be ascribed to perisinusoidal fibrosis impeding the transfer of the dye from blood to hepatocytes across the spaces of Disse. The other possible mechanisms for the decreased BSP clearancenamely, hepatocytic dysfunction and reduced liver blood flow-are unlikely, as the hepatocytes are morphologically normal and liver blood flow has been found to be not or only slightly diminished (Benhamou et al., 1962; Iber, 1970; Huet et al., 1975; Villeneuve et al., 1976) in idiopathic portal hypertension.

The cause of perisinusoidal fibrosis in our patient is uncertain. The fortuitous coincidence of renal transplantation and perisinusoidal fibrosis cannot be ruled out, but is unlikely, as renal transplantation and idiopathic portal hypertension are very uncommon conditions in the general population in France. In a small number of patients with idiopathic portal hypertension or hepatoportal sclerosis, the liver lesion has been attributed to prolonged administration of arsenic (Morris et al., 1974; Huet et al., 1975) or methotrexate (Talerman and Thompson, 1966; Podurgiel et al., 1973), hypervitaminosis A (Russell et al., 1974), inhalation of vinyl chloride (Thomas et al., 1975; Smith et al., 1976); none of these factors was implicated in our 
patients. Hepatic fibrosis has been reported in a few patients receiving 6-mercaptopurine (Lascari et al., 1968) or azathioprine (Zarday et al., 1972; Du Vivier et al., 1974; Freiberger et al., 1974), two chemically related compounds which were administered to our patients; if, according to our hypothesis, perisinusoidal fibrosis and hepatoportal sclerosis are two stages of a unique entity, these reports strongly suggest that 6-mercaptopurine and azathioprine might be the cause of the liver lesion and portal hypertension in our patients. The role of renal transplantation itself in the determination of perisinusoidal fibrosis, although conjectural, cannot be excluded. It may be relevant to mention that, in schistosomiasis Mansoni with specific lesions confined to the portal tracts, non-specific perisinusoidal fibrosis affecting the whole length of the sinusoids has been demonstrated and attributed to deposition of complexes of antibody and antigen produced by the parasites (Grimaud and Borojevic, 1977); similarly, perisinusoidal fibrosis after renal transplantation might result from deposition of immune complexes the presence of which is common in these patients (Palusuo et al., 1976).

The authors thank Professor François Potet and Dr Nicole Brousse for advice and assistance.

\section{References}

Benhamou, J. P., Guillemot, R., Tricot, R., Léger, R., and Fauvert, R. (1962). Hypertension portale essentielle. Presse Médicale, 70, 2397-2399.

Boyer, J. L., Hales, M. R., and Klatskin, G. (1974). "Idiopathic" portal hypertension due to occlusion of intrahepatic portal veins by organized thrombi. Medicine (Baltimore), 53, 77-91.

Boyer, J. L., Sen Gupta, K. P., Biswas, S. K., Pal, N. C., Basu Mallick, K. C., Iber, F. L., and Basu, A. K. (1967). Idiopathic portal hypertension. Comparison with the portal hypertension of cirrhosis and extrahepatic portal vein obstruction. Annals of Internal Medicine, 66, 41-68.

Du Vivier, A., Munro, D. D., and Verbov, J. (1974). Treatment of psoriasis with azathioprine. British Medical Journal, 1, 49-51.

Freiberger, Z., Anuras, S., Koff, R. S., and Bonney, W. W. (1974). Chronic active hepatitis without hepatitis B antigenemia in renal transplant recipients. Report of three cases. Gastroenterology, 66, 1187-1194.

Grimaud, J. A., and Borojevic, R. (1977). Chronic human schistosomiasis mansoni. Pathology of the Disse's space. Laboratory Investigation, 36, 268-273.

Huet, P. M., Guillaume, E., Côté, J., Légaré, A., Lavoie, P., and Viallet, A. (1975). Non cirrhotic presinusoidal portal hypertension associated with chronic arsenical intoxication. Gastroenterology, 68, 1270-1277.

Iber, F. L. (1969). Obliterative portal venopathy of the liver and "idiopathic portal hypertension". Annals of Internal Medicine, 71, 660-661.

Iber, F. L. (1970). Portal hypertension in the presence of normal liver morphology. Annals of the New York Academy of Sciences, 170, 115-126.

Imanaga, H., Yamamoto, S., Ishiguro, M., Owa, J.,
Imamura, R., Hirano, H., Rokuo, K., Ando, F., Suzuki, F., Arai, T., Doi, A., Yokoyama, Y., Mizutani, T., and Sawada, M. (1962). Classification and treatment of portal hypertension. Nagoya Journal of Medical Science, 24, 254-264.

Kluge, T., Sommerschild, H., and Flatmark, A. (1970). Sinusoidal portal hypertension. Surgery, 68, 294-300.

Lascari, A. D., Givler, R. L., Soper, R. T., and Hill, L. F. (1968). Portal hypertension in a case of acute leukemia treated with antimetabolites for ten years. New England Journal of Medicine, 279, 303-306.

Lortat-Jacob, J. L., Dupuy, R., Fauvert, R., Maillard, J. N., and Benhamou, J. P. (1967). Les blocs intrahépatiques en dehors des cirrhoses communes. Résultats de l'anastomose portocave. Bulletins et Mémoires de la Société Médicale des Hôpitaux de Paris, 113, 1069-1074.

Mendenhall, C. L., Sherman, J., and Chedid, A. (1974). Intermittent idiopathic portal hypertension. A case report. Gastroenterology, 67, 142-148.

Mikkelsen, W. P., Edmondson, H. A., Peters, R. L., Redeker, A. G., and Reynolds, T. B. (1965). Extra- and intrahepatic portal hypertension without cirrhosis (hepatoportal sclerosis). Annals of Surgery, 162, 602-620.

Miller, M. C., and Brandt, J. L. (1962). Portal hypertension in the absence of both liver disease and vascular obstruction. American Journal of Digestive Diseases, 7, 442-448.

Morris, J. S., Schmid, M., Newman, S., Scheuer, P. J., and Sherlock, S. (1974). Arsenic and noncirrhotic portal hypertension. Gastroenterology, 66, 86-94.

Palusuo, T., Kano, K., Anthone, S., Gerbasi, J. R., and Milgram, F. (1976). Circulating immune complexes after kidney transplantation. Transplantation(Baltimore), 21, 312316.

Podurgiel, B. J., McGill, D. B., Ludwig, J., Taylor, W. F., and Muller, S. A. (1973). Liver injury associated with methotrexate therapy for psoriasis. Mayo Clinic Proceedings, 48, 787-792.

Rappaport, A. M. (1975). Anatomic considerations. In Diseases of the Liver, pp. 31-40. Edited by L. Schiff. Lippincott: Philadelphia.

Russell, R. M., Boyer, J. L., Bagheri, S. A., and Hruban, Z. (1974). Hepatic injury from chronic hypervitaminosis A resulting in portal hypertension and ascites. New England Journal of Medicine, 291, 435-440.

Sama, S. K., Bhargava, S., Gopi Nath, N., Talwar, J. R., Nayak, N. C., Tandon, B. N., and Wig, K. L. (1971). Noncirrhotic portal fibrosis. American Journal of Medicine, 51, 160-169.

Smith, P. M., Crossley, I. R., and Williams, D. M. J. (1976). Portal hypertension in vinyl-chloride production workers. Lancet, 2, 602-604.

Talerman, A., and Thompson, R. B. (1966). Hepatic fibrosis in a child possibly due to prolonged methotrexate. Journal of Clinical Pathology, 19, 81-82.

Tandon, B. N., Lakshminarayanan, R., Bhargava, S., Nayak, N. C., and Sama, S. K. (1970). Ultrastructure of the liver in non-cirrhotic portal fibrosis with portal hypertension. Gut, 11, 905-910.

Thomas, L. B., Popper, H., Berk, P. D., Selikoff, I., and Falk, H. (1975). Vinyl-chloride-induced liver disease. From idiopathic portal hypertension (Banti's syndrome) to angiosarcomas. New England Journal of Medicine, 292, 17-22.

Tisdale, W. A., Klatskin, G., and Glenn, W. W. L. (1959). Portal hypertension and bleeding esophageal varices. Their occurrence in the absence of both intrahepatic and extrahepatic obstruction of the portal vein. New England Journal of Medicine, 261, 209-218.

Villeneuve, J. P., Huet, P. M., Joly, J. G., Marleau, D., 
Côté, J., Légaré, A., Lafortune, M., Lavoie, P., and Viallet, A. (1976). Idiopathic portal hypertension. American Journal of Medicine, 61, 459-464.
Zarday, Z., Veith, F. J., Gliedman, M. L., and Soberman, R. (1972). Irreversible liver damage after azathioprine. Journal of the American Medical Association, 222, 690-691.

\section{The May 1979 Issue}

\section{THE MAY 1979 ISSUE CONTAINS THE FOLLOWING PAPERS}

Plasma prednisolone levels and adrenocortical responsiveness after administration of prednisolone21-phosphate as a retention enema D. A. H. LEE, G. M. TAYLOR, V. H. T. JAMES, AND G. WALKER

Effect of ouabain on Na,K-ATPase and electrolyte transport in the dog ileum in vivo $\mathrm{N}$. W. READ, G. J. KREJS, V. E. JONES, AND J. S. FORDTRAN

Variations in the incidence and the spatial distribution of patients with primary acute pancreatitis in Nottingham 1969-76 J. B. BOURKE, J. A. GIGGS, AND D. $S$. EBDON

Chronic persistent hepatitis: hepatitis $\mathbf{B}$ virus markers and histological follow-up R. C. CHADWICK, J. GALIZZI, JR, J. HEATHCOTE, T. LYSSIOTIS, B. J. COHEN, P. J. SCHEUER, AND S. SHERLOCK

Chronic oral arsenic intoxication as a possible aetiological factor in idiopathic portal hypertension (non-cirrhotic portal fibrosis) in India $\mathrm{D}$. $\mathrm{V}$. DATTA, S. K. MITRA, P. N. CHHUTTANI, AND R. N. CHAKRAVARTI

Mechanisms responsible for antibody-dependent, cell-mediated cytotoxicity to isolated hepatocytes in chronic active hepatitis C. GonZales, A. M. G. COCHRANE, A. L. W. F. EDDLESTON, AND ROGER WILLIAMS
Gastric acid secretion rate and buffer content of the stomach after a rice- and a wheat-based meal in normal subjects and patients with duodenal ulcer K. N. JALAN, D. MAHAlanABIS, T. K. MAITRA, AND S. K. AGARWAL

Endogenous prostaglandins in peptic ulcer disease R. BAKER, B. M. JAFFE, AND C. W. VENABLES

Rectal absorption of short chain fatty acids in the absence of chloride N. I. MCNEIL, J. H. CUMMINGS, AND W. P. T. JAMES

\section{Clinical trials}

Effect of long-term cimetidine on gastric acid secretion, serum gastrin, and gastric emptying J. A. H. FORREST, M. R. FETTES, G. P. MCLOUGHLIN, AND R. C. HEADING

Double-blind trial of the use of transfer factor in the treatment of Crohn's disease F. R. VICARY, J. D. CHAMBERS, AND P. DHILLON

\section{Case reports}

Turcots's syndrome and its mode of inheritance H. ITOH, K. OHSATO, T. YAO, M. IIDA, AND H. WATANABE

Progress report

The Paneth cell M. J. SANDOW AND R. WHITEHEAD

Notes and activities; Books

The British Society of Gastroenerology page A433

Copies are still available and may be obtained from the PUBLISHING MANAGER, BRITISH MEDICAL ASSOCIATION, TAVISTOCK SQUARE, LONDON WC1H 9JR, price $£ 3 \cdot 50$, including postage 